\title{
EDITORIAL
}

\section{Actualidad de la genómica clínica en el área cardiovascular en Colombia}

\section{Current state of cardiovascular genomics in Colombia}

\author{
Juan Esteban Gallo
}

\author{
Director científico Genoma CES, Medellín, Colombia
}

Recibido el 18 de octubre de 2016; aceptado el 21 de octubre de 2016

Disponible en Internet el 12 de enero de 2017

La genómica clínica ha avanzado de forma exponencial en el mundo durante la última década, debido a la innovación en el campo de las técnicas de secuenciación, que han hecho que los procedimientos sean más cada vez más rápidos y económicos. En la actualidad se plantea un escenario en el cual el médico tiene a su disposición ayudas diagnósticas de última generación en técnicas moleculares y de secuenciación. A continuación se revisan brevemente las ayudas diagnósticas basadas en el conocimiento genético del paciente y su estado actual en el mercado colombiano.

Antes de las tecnologías de secuenciación de nueva generación, la alternativa para obtener la información genética de un paciente eran los métodos de secuenciación tradicionales, basados en la tecnología Sanger. Para obtener la secuencia de un gen específico, primero se escogía el gen blanco de interés. El médico debía tener una idea sobre cual o cuales de estos genes podían estar involucrados en la enfermedad de su paciente, algo que puede ser relativamente complejo en el momento de tomar una decisión. La secuenciación de cualquier gen puede ser engorrosa debido a la gran diferencia de tamaños y número de exones entre genes, hecho relevante para entender la forma por la cual se secuencian genes por métodos tradicionales. Para estudios genéticos de un gen, en primer lugar se amplifican todas las partes codificantes del mismo, por medio de la técnica de PCR (polymerase chain reaction). Por ejemplo, el

Correo electrónico: jegallo@ces.edu.co gen SCN5A, posee 28 exones con un tamaño aproximado de $80 \mathrm{~kb}$. Esto implica muchos ciclos de amplificación por PCR, situación en la cual se debe amplificar cada exón de forma independiente, incrementando así costos y tiempo de personal capacitado en el área de la biología molecular. En los casos en los que la secuenciación de un solo gen tenga validez clínica, tomando SCN5A como ejemplo, la complejidad de procesos de laboratorio se opaca con el gran beneficio que tendrán los pacientes al conocer la posible causa genética de su enfermedad o evento cardiovascular. Pero, como las condiciones cardiovasculares no son enfermedades clásicas mendelianas, en la mayoría de los casos no es posible tomar una decisión fácil sobre cual gen específico estudiar.

La era de la secuenciación de nueva generación permitió expandir un poco más las pruebas genéticas que se pueden hacer en paralelo. La secuenciación de paneles de genes asociados a ciertas enfermedades puede ser más útil al momento de tomar una decisión en comparación con la información que brinda la secuenciación de un solo gen. Existen muchos paneles de genes en el mercado, que en el caso de las enfermedades cardiovasculares pueden variar entre una docena a varias centenas de genes. Muchos de estos son kits comerciales que tienen una lista de genes fijos que serían secuenciados. La disponibilidad de estos paneles fluctúa en los laboratorios de referencia, dependiendo en la tecnología de secuenciación que se implemente. En términos económicos, pueden ser un poco más costosos que la secuenciación de un solo gen, pero la utilidad clínica incrementa con la cantidad de información que se obtiene. 
La literatura ha demostrado que en ciertos casos, el gen causante de la patología no está incluido en las listas completas que se hallan disponibles para el estudio en estos paneles, debido a que el genoma humano aun está en estudio y la asociación de genes a enfermedades aun no ha llegado a su punto final.

Adicionalmente, existen otros paneles que sí son muy efectivos y útiles. Estos no secuencian genes asociados a enfermedades, sino que se enfocan en genes cuyas funciones están relacionadas con el metabolismo e interacción con medicamentos. Estas pruebas se conocen como pruebas de fármaco-genómica, las cuales permiten tener información sobre como un paciente reaccionará al tomar un medicamento, si favorable, no respondedor, o dosis-dependiente para el mismo. En el área cardiovascular existe un gran número de medicamentos que se incluyen en estas pruebas, entre estos antiarrítmicos, anticoagulantes, antianginosos, antiplaquetarios, beta-bloqueadores, bloqueadores de canales de calcio, inhibidores de la fosfodiesterasa y estatinas.

Estos resultados en combinación con pruebas genómicas de genes asociados a las enfermedades, permiten entender las razones por las cuales ciertos pacientes no responden de forma adecuada a determinados tratamientos. Como ejemplo pueden citarse los no respondedores a medicamentos para el colesterol, para quienes pueden existir varios escenarios:

1) El paciente tiene mutaciones en genes asociados directamente a procesos del cuerpo que procesan el colesterol como los genes LDL y Apo B. Estos pacientes no responden al medicamento ya que su genética no permite regular los niveles de colesterol.

2) El paciente no tiene mutaciones en los genes asociados con éstos, pero sí en los de citocromo P450 involucrados en el metabolismo de los medicamentos, causando una respuesta no adecuada en el tratamiento.

3) El paciente tiene mutaciones en combinación 1 y 2 . En este caso, existe evidencia múltiple para considerar medicamentos de nueva generación que quizás pueden tener mayor efectividad pero las causas genéticas de altos niveles de colesterol influyen en el resultado.

Por otro lado, ¿qué hacer cuando se trata de estudiar enfermedades cardiovasculares huérfanas que no tienen suficientes estudios de genómica clínica, y que no se encuentran paneles de genes disponibles para ayudar en el diagnóstico? Hoy la prueba más inclusiva con utilidad clínica es la secuenciación del exoma completo. Esta técnica se basa en la secuenciación de todas las partes codificantes del genoma humano. En su última anotación, se reportó que el genoma humano codifica aproximadamente para 20.000 genes. Este panorama completo permite tener mayor claridad sobre cómo el cuerpo de forma íntegra mantiene un balance de funciones por medio de sus estructuras protéicas lo cual permite al médico tratar a su paciente con medicina de precisión y personalizada.

La implementación de la secuenciación del exoma completo, permite, de forma relativamente económica, obtener toda la información genética que codificará proteínas cuyas funciones estarán involucradas en el mantenimiento, el desempeño y la funcionalidad sana del cuerpo humano. Al ser la más inclusiva, no significa que sea la más utilizada. Muchos médicos aun ordenan las pruebas de secuenciación de un solo gen.

Quizás el mito sobre lo costosas que pueden ser las pruebas de panel o exoma completo, o la falta de cobertura en el plan obligatorio de salud, pueden ser las razones por las cuales aun se ordenan exámenes de un solo gen. Por su parte, existe un gran costo-beneficio al secuenciar todos los genes de un individuo versus un gen a la vez. Respecto a costos, la secuenciación de un gen puede valer aproximadamente 1 a 3 millones de pesos, y en algunos casos más. El precio de secuenciación del exoma es cercano a los 6 millones de pesos. Por simplicidad de la comparación, supongamos que el mismo usuario se realiza la secuenciación de SCN5A por un costo de 2 millones de pesos. Si comparamos el costo-beneficio de obtener la información de un gen por 2 millones de pesos, un exoma completo por 6 millones de pesos, la secuenciación de cada gen por medio de exoma (teniendo en cuenta que el genoma humano tiene aproximadamente 20.000 genes) sería de 300 pesos. Este ejercicio de costo-beneficio aclara que la secuenciación del exoma completo sigue siendo una mejor opción cuando se requieren pruebas genéticas. En lo concerniente a la cobertura por el POS, el Ministerio de Salud y Protección Social emitió la resolución 5592 de 2015 donde actualiza integralmente el Plan de Beneficios en salud con cargo a la Unidad de Pago por Capitación del Sistema General de Seguridad Social en Salud. En los códigos 90.8.4.02 al 90.8.4.39 se menciona la cobertura del sistema para pruebas de tipo molecular/genéticas/genómicas. En particular, los códigos 90.8.4.12 (estudio molecular de enfermedades), 90.8.4.19 (estudios genéticos de ADN mitocondrial), 90.8.4.20 (estudios moleculares de genes), 90.8.4.22 (estudio molecular de exones) y 90.8.4.24 (estudio molecular de mutaciones) caben dentro de la interpretación que la secuenciación de exoma completo pudiera ser implementada para estas pruebas.

En conclusión, el uso de secuenciación de exoma completo es una prueba que puede tener validez clínica suficiente en el momento de emitir un diagnóstico completo. Los beneficios que pueden tener los pacientes superan los riesgos. La presencia de variantes patogénicas genómicas no significa un $100 \%$ de probabilidad de desarrollar algún problema médico, ya que pueden existir otros factores aun no descritos. Para muchas enfermedades que quizás sean tratables esta información le permitirá al paciente y al médico implementar procesos de prevención oportunos. 